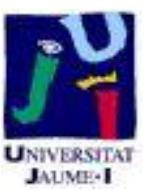

Título artículo / Títol article: With a litte help from my assistant: buffering the negative effects of emotional dissonance on dentist performance

Autores / Autors

Rodrígez Sánchez, Alma María ; Hakanen, Jari ; Perhoniemi, Riku ; Salanova Soria, Marisa

Revista:

Community dentistry and oral epidemiology, 2013, vol. 41 , no 5

Versión / Versió:

Cita bibliográfica / Cita bibliogràfica (ISO 690):

url Repositori UJI:
Postprint del autor

RODRÍGUEZ - SÁNCHEZ, Alma M., et al. With a little help from my assistant: buffering the negative effects of emotional dissonance on dentist performance. Community dentistry and oral epidemiology, 2013, vol. 41, no 5, p. 415-423

http://hdl.handle.net/10234/94170 


\section{Community

\section{With a little help from my assistant: buffering the negative effects of emotional dissonance on dentist performance}

Rodríguez-Sánchez AM, Hakanen JJ, Perhoniemi R, Salanova M. With a little help from my assistant: buffering the negative effects of emotional dissonance on dentist performance. Community Dent Oral Epidemiol 2013. C 2013 John Wiley \& Sons A/S. Published by Blackwell Publishing Ltd

\begin{abstract}
Objective: In this study, we hypothesized that dentist' interpersonal resources (good cooperation with one's assistant) together with their personal resources (optimism) buffer the negative effects of emotional dissonance (a demand that occurs when there is a difference between felt and displayed emotions) on job performance (in-role and extra-role performance) over time. Method: We carried out Hierarchical Regression Modeling on a sample of 1954 Finnish dentists who participated in a two-wave 4-year longitudinal study. Results: Results showed that good cooperation with dental assistants buffered the negative effects of emotional dissonance on both in-role and extra-role performance among the dentists in the long term. However, unexpectedly, dentists' high optimism did not buffer their in-role nor extra-role performance over time under conditions of experiencing high emotional dissonance. Conclusions: We conclude that interpersonal job resources such as good cooperation with one's colleagues may buffer the negative effect of emotional dissonance on dentists' job performance even in the long term, whereas the role of personal resources (e.g., optimism) may be less important for maintaining high job performance under conditions of emotional dissonance. The study novelties include the test of the negative effects of emotional dissonance on long-term performance in dentistry and the identification of the job rather than personal resources as the buffers against the negative effects of emotional dissonance on long-term performance.
\end{abstract}

Alma M. Rodríguez-Sánchez ${ }^{1}$, Jari J. Hakanen $^{2}$, Riku Perhoniemi ${ }^{2}$ and Marisa Salanova $^{3}$

${ }^{1}$ Department of Business Administration, Universitat Jaume I, Castellón, Spain, ${ }^{2}$ Finnish Institute of Occupational, Health, Helsinki, Finland, ${ }^{3}$ Department of Social Psychology, Wont Research Team, Universitat Jaume I, Castellón, Spain
Key words: dentists; emotional dissonance; job resources; optimism; performance

Alma M. Rodríguez-Sánchez, Department of Business Administration, Universitat Jaume I. Campus de Riu Sec s/n 12071, Castellón, Spain

Tel.: +34964728556

Fax: +34 964728629

e-mail: alrodrig@uji.es

Submitted 9 July 2012;

accepted 22 December 2012
Human service professionals, such as dentists, belong to an occupational group characterized by high levels of emotion work (1). The drawback of having high clinical autonomy is that dentistry may become a lonely job. For instance, dentists working in solo practice are more liable to report high levels of emotional exhaustion and low levels of personal accomplishment (2). Another key factor associated with burnout among dentists is difficult patient contacts $(3,4)$. For example, dentists often have to work in an emotionally demanding atmosphere, and sometimes expressing emotions that that they do not 'truly' feel. According to previous studies, this discrepancy between felt and expressed emotions in client work, also called emotional dissonance, impacts negatively on employee well-being and performance, which in turn can negatively affect the quality of client service $(5,6)$. However, to our knowledge, there are no previous studies on the impacts of emotional dissonance on dentists' jobs.

Outside dentistry, most studies on emotion work have focused on its negative consequences, such as burnout or poor performance $(7,8)$. However, from 
an applied point of view, little empirical evidence exists on whether the negative impact of emotional dissonance extends to future performance, and if so, how dentists cope with emotional demands and mitigate their negative effects. Therefore, it is important to identify resources that could help dentists to maintain good performance level even in emotionally demanding situations. In this study, by following the framework of the Job DemandsResources Model $(9,10)$, we aimed to examine the buffering role of both job and personal resources in alleviating the negative effects of emotional dissonance on job performance over time. From a theoretical point of view, this study will contribute to a better understanding of the underlying psychological mechanisms by which specific job and personal resources may act as buffers against the potential negative effects of emotional dissonance on performance. From a practical point of view, it is important to know what kinds of resources - workrelated or individual - may protect dentists and help maintain their performance level even in conditions of high emotional dissonance. By identifying such resources, it becomes possible to develop better management and work practices and thereby promote not only dentists' psychological health, but also their performance.

\section{Emotional dissonance and its consequences}

Emotion work involves regulating (enhancing, faking or suppressing) emotions according to the requirements of the organization $(1,11)$ and is often differentiated into four dimensions: (i) the requirement to display positive emotions, (ii) the requirement to display and handle negative emotions, (iii) the requirement to sense the emotion of the interactive partner (or empathy) and (iv) the dissonance between felt and displayed emotions (emotional dissonance) (12).

Past research has shown that the most demanding and harmful facet of emotion work is emotional dissonance (13-15), which occurs when an employee's expressed emotions are in conformity with organizational rules but do not represent his or her true feelings $(1,15)$. Emotional dissonance seems to place a toxic demand on the employee, given that it has been found to be a source of work stress and to cause burnout $(13,16,17)$ which is a common problem also in dentistry $(10,18)$. Moreover, emotional dissonance may also have negative consequences for organizations, not only because of its negative effects on employee well-being and motivation (19) but also because it may negatively affect job performance $(5,7)$ and increase turnover intentions (20). Therefore, we investigated whether the specific job and personal resources may help dentists to cope with such specific emotional demands as emotional dissonance.

\section{Coping with emotional dissonance: job and personal resources}

Empirical research is scarce on how to cope with this most stressful aspect of emotional demands at work, and on the resources that can buffer its negative effects at work. To our knowledge, no such studies have been carried out in dentistry. Therefore, by using the job demands-resources model (JD-R model; 9), our main aim was to test how a specific job resource (good cooperation with one's assistant) and a specific personal resource (optimism), may mitigate the negative effects of emotional dissonance on long-term in-role and extra-role performance at work. In-role performance (or task performance) includes role-prescribed activities which employees perform in exchange for pay. Extra-role performance (or contextual performance) includes activities as volunteering to carry out actions that are not formally part of the job; helping others; endorsing and supporting organizational objectives; and persisting with extra effort to successfully complete one's task activities (21). According to the JD-R model, employee well-being, and in turn job performance (22), are related to diverse features of work that can be conceptualized as either job demands (physical, social, or organizational aspects of the job that require sustained physical or psychological effort) or job resources (those aspects of work that may reduce job demands, are functional in achieving work goals, or stimulate personal growth and development) (9). Research provides evidence that job resources may buffer the impact of job demands on job strain. For example, social support has been found to play a relevant role in moderating the relationship between emotional demands such as emotional dissonance and employee well-being (23-26).

Although more research is needed regarding the role of social support in dentistry in particular, some studies have found that practical and emotional support are important characteristics of good work in dentistry $(27,28)$. Thus, having friendly and helpful colleagues - for dentists, the closest colleagues are often the chair-side assistants they work with - motivates, and contributes to improving well-being at work by reducing the negative effects of emotional dissonance (29). In other 
words, collaborating with close colleagues, receiving instrumental help and having an emotionally good relationship with one's coworkers may act as a powerful resource against emotionally demanding situations and therefore moderate the negative impact of emotional dissonance on the proper performance of tasks, also enabling extra-role performance. Hence, in dentistry, a good cooperation with dentist assistant may be an important job resource. To note that although social support and cooperation are two related but independent concepts, in the present study, we focus on the role of a specific part of social support, that is, the cooperation with the assistant. However, to our knowledge, no empirical research has been carried out specifically on the buffering role of this specific job resource (cooperation with one's assistant) as regards emotional dissonance and job performance. In fact, although the negative effects of emotional dissonance are likely to be long lasting, we expect that cooperation with one's assistant as a salient job resource will act as a buffer variable across time.

Therefore, we expect that even after controlling for baseline (T1) in-role and extra-role job performance:

Hypothesis 1a: Having good T1 cooperation with one's assistant will buffer the negative effects of T1 emotional dissonance on T2 in-role performance.

Hypothesis 1b: Having good T1 cooperation with one's assistant will buffer the negative effects of $\mathrm{T} 1$ emotional dissonance on T2 extra-role performance.

In addition to job resources, personal resources may also be useful for overcoming the negative consequences of stressors. Personal resources are positive self-evaluations that are linked to resiliency and refer to individuals' sense of their ability to successfully control and impact upon their environment (30). Therefore, following the expansion of the JD-R model (31), personal resources may play an important role in the model's motivational process. According to the JD-R model, job demands such as emotional dissonance may trigger a health impairment process that can lead to burnout and consequently to poorer health and performance in the long term. In contrast, job resources exert their positive influence on motivational outcomes such as organizational commitment (32). However, to our knowledge, there is no empirical evidence on emotional dissonance research of the buffering effects of personal resources on performance outcomes.

In this study, we focused on optimism as a personal resource. Optimism is the tendency to believe that one will generally experience good outcomes in life, and it has been related, for example, to higher well-being levels (33). Optimists are better able to confront threatening situations because they adopt active coping strategies (34), and as a result, they adapt well at work (35). Moreover, several studies have shown that optimism, as an important personal resource, has acted as a moderator between demanding situations and well-being and health outcomes $(36,37)$. Especially in health care settings, more optimistic nurses report lower levels of emotional exhaustion and higher work engagement when experiencing higher role stress than do less optimistic nurses (38). Additionally, optimism can be related also to organizational outcomes such as performance. Indeed, optimism has been linked to performance in diverse settings, such as class performance (39), sales performance (40), and leadership behaviors (41). However, the number of studies on the relationships between optimism and job performance in emotionally demanding environments is lacking, and especially nonexistent in dentistry.

Considering the above, although no specific research has been conducted on either the buffering role of optimism against the negative effect of emotional dissonance on performance, or on its long-term effects, we expect that optimism, as a stable personal resource, similarly to good cooperation with one's assistant, may act as a buffering resource in emotionally demanding situations, specifically in dentistry. Based on this, we formulated the following hypotheses:

Hypothesis 2a: T1 optimism will buffer the negative effects of T1 emotional dissonance on T2 inrole performance.

Hypothesis 2b: T1 optimism will buffer the negative effects of T1 emotional dissonance on T2 extra-role performance.

\section{Methods}

Participants and procedure

This study was part of a longitudinal research project focusing on psychosocial working conditions 
and well-being in Finnish dentistry. The current follow-up data were gathered through a postal questionnaire survey between January and April, in both 2006 and 2010. The 4-year interval for follow-up was based on practical decisions by the Finnish Dental Association and on financial arrangements. Response rates were $84 \%$ in 2006 and $86 \%$ in 2010 . Of the final sample $(N=1964)$, $76 \%$ were women and $63.5 \%$ were employed in the public sector. The mean age of the respondents was $51.4(\mathrm{SD}=7.86)$, and the average job tenure was $25.1(\mathrm{SD}=8.54)$. To note that we only included in the study those dentists who participated in both times 2006 and 2010.

We investigated selective dropouts by comparing the demographics and the study variables of the participants in both 2006 (T1) and 2010 (T2) to those who did not participate in $2010(N=583)$. Women $[76 \%$ versus $67 \% ; \quad \chi 2 \quad(1)=16.91$, $P<0.001]$, dentists employed in the public sector $[64 \%$ versus $56 \% ; \chi 2(1)=9.52, P<0.01]$ and younger participants (47.4 versus 52.2 years of age, $P<0.001)$ were slightly over-represented in the follow-up data. The respondents who participated at both time points reported somewhat worse cooperation with their assistants (dental nurses) than those who did not participate at T2 [F (1) $=137.64, P<0.001]$. The groups did not differ in emotional dissonance, optimism, in-role performance or extra-role performance at T1. Therefore, and also because of a high response rate, we assume that selective dropout did not bias our results.

\section{Measures}

Emotional Dissonance at $\mathrm{T} 1$ was assessed using a four-item scale developed by Zapf (12) (e.g.,'How often in your job do you have to display emotions that do not agree with your actual feelings towards clients?') and rated on a five-point scale ranging from ' 1 = very rarely $/$ never' to $` 5=$ very often (several times an hour)'. Cronbach's alpha was 0.88 .

Cooperation with one's assistant at T1 was measured with a self-constructed four-item scale (42). The items (e.g., 'Does cooperation with your assistant run smoothly?') were rated on a five-point scale ranging from ' $1=$ very rarely' to ' $5=$ very often/always'. Cronbach's alpha was 0.74 .

Optimism at T1 was assessed using three items adapted from the Life Orientation Test (LOT-R; 43). We used the three positively phrased items (e.g., 'In uncertain times I usually expect the best') included in LOT-R, because in this study we wanted to focus particularly on optimism (rather than pessimism). Several studies have supported the assumption that optimism and pessimism are distinct albeit negatively related constructs that load on separate factors and that the negatively phrased items in LOT-R measure pessimism rather than optimism $(44,45)$. The items were rated on a five-point scale ranging from ' $1=$ totally disagree' to ' $5=$ totally agree'. Cronbach's alpha was 0.86 .

In-role performance was assessed with nine items by Goodman (21). The items (e.g., 'I demonstrate expertise in all job-related tasks', 'I achieve the objectives of the job') were rated on a seven-point scale from ' $1=$ totally disagree' to ' $7=$ totally agree'. Cronbach's alphas were $\alpha_{\mathrm{T} 1}=0.89$, and $\alpha_{\mathrm{T} 2}=0.89$.

Extra-role performance consisted of seven items (21) (e.g., 'I volunteer to do things not formally required by the job', 'I help other employees with their work when they have been absent'). The items were rated on a seven-point scale from $' 1=$ totally disagree' to ' $7=$ totally agree'. Cronbach's alphas were $\alpha_{\mathrm{T} 1}=0.86$ and $\alpha_{\mathrm{T} 2}=0.87$.

\section{Data analysis}

We used SPSS statistical package 18 for hierarchical regression analyses ( IBM corporation, SPSS Inc. Chicago, IL, USA). The preliminary factor analyses confirmed that emotional dissonance, cooperation with one's assistant, and optimism could be distinguished empirically from each other. Predictor variables were centered around their means, and interaction terms were then computed, as recommended by Aiken (46). In each model, to predict performance at T2, we first controlled for performance measured at $\mathrm{T} 1$, age, gender, and the sector (public/private). In the next step, we added emotional dissonance and the resource variable to the model. Finally, in the third step, we included the emotional dissonance $x$ resource product term in the model.

\section{Results}

\section{Descriptives}

Table 1 shows the means, standard deviations, and the correlations of the variables used in this study. All the correlations were in the expected direction.

\section{Hypothesis testing}

The results of hierarchical regression analyses showed that T1 good cooperation with one's assistant positively predicted both $\mathrm{T} 2$ in-role performance 
Table 1. Means, standard deviations, and correlations between study variables among Finnish Dentists $(N=1964)$

\begin{tabular}{|c|c|c|c|c|c|c|c|c|c|c|c|}
\hline Variables & $M$ & $\mathrm{SD}$ & 1 & 2 & 3 & 4 & 5 & 6 & 7 & 8 & 9 \\
\hline 1. Gender $(1=$ female; $2=$ male $)$ & - & - & - & - & - & - & - & - & - & - & - \\
\hline 2. Age ${ }_{\mathrm{T} 1}$ & 47.41 & 7.88 & 0.13 & - & - & - & - & - & - & - & - \\
\hline 3. Sector $($ public $=1 ;$ private $=2$ ) & - & - & 0.15 & 0.11 & - & - & - & - & - & - & - \\
\hline 4. Cooperation with one's assistant $\mathrm{T} 1$ & 3.55 & 0.64 & 0.00 & 0.11 & 0.04 & - & - & - & - & - & - \\
\hline 5. Optimism ${ }_{\mathrm{T} 1}$ & 3.83 & 0.73 & 0.05 & -0.01 & 0.08 & 0.23 & - & - & - & - & - \\
\hline 6. Emotional dissonance $\mathrm{T} 1$ & 2.54 & 0.83 & -0.15 & -0.08 & -0.14 & -0.13 & -0.27 & - & - & - & - \\
\hline 7. In-role performance $\mathrm{T} 1$ & 5.09 & 0.90 & 0.15 & -0.12 & 0.21 & 0.20 & 0.36 & -0.23 & - & - & - \\
\hline 8. Extra-role performance $\mathrm{T} 1$ & 5.19 & 0.89 & 0.07 & 0.01 & 0.12 & 0.23 & 0.21 & -0.07 & 0.32 & - & - \\
\hline 9. In-role performance $\mathrm{T} 2$ & 5.13 & 0.91 & 0.15 & -0.10 & 0.23 & 0.19 & 0.33 & -0.20 & 0.68 & 0.28 & - \\
\hline 10. Extra-role performance ${ }_{\mathrm{T} 2}$ & 5.23 & 0.92 & 0.07 & -0.02 & 0.17 & 0.23 & 0.24 & -0.06 & 0.27 & 0.65 & 0.37 \\
\hline
\end{tabular}

Correlations of $>0.08$ are statistically significant, $P<0.001$; correlations between 0.06 and 0.08 are statistically significant, $P<0.01$.

and T2 extra-role performance, even after controlling for the impact of respective performance at baseline (Table 2). Similarly, T1 optimism positively predicted both forms of performance at $\mathrm{T} 2$. In addition, T1 emotional dissonance negatively predicted $\mathrm{T} 2$ in-role performance but did not predict T2 extra-role performance, although correlations were both negative and significant.

As can be seen from Table 2, we found support for two of four hypothesized longitudinal interaction effects on job performance at T2 after controlling for the main effects of emotional dissonance and cooperation with assistant/optimism and job performance at T1. More specifically, good cooperation with one's assistant had a moderating effect on the relationship both between emotional dissonance and T2 in-role performance, and between emotional dissonance and T2 extra-role performance. In addition, optimism had a moderating effect on the relationship between emotional dissonance and T2 in-role performance. However, we could not find support for the interaction effect of emotional dissonance $x$ optimism on $\mathrm{T} 2$ extra-role performance.

To examine further the direction of the interaction effects, we produced graphical representations of the moderation effects using the procedure of simple slope analyses (46). Figures 1 and 2 show that for cooperation the interaction effects were in the expected direction. Thus, in high emotional dissonance situations, the negative effect of emotional dissonance at T1 on in-role performance at T2 was buffered when good cooperation with one's assistant at T1 was high (Fig. 1). In other words, T1

Table 2. Regression of in-role performance extra-role performance at T2 on emotional dissonance, optimism, and cooperation with assistant at $\mathrm{T} 1, N=1964$

\begin{tabular}{|c|c|c|c|c|c|c|c|}
\hline \multirow[b]{2}{*}{ Step } & \multirow[b]{2}{*}{ Model } & \multicolumn{3}{|c|}{ In-role performance at $\mathrm{T} 2$} & \multicolumn{3}{|c|}{ Extra-role performance at T2 } \\
\hline & & $\beta$ & $R^{2}$ change & $F$ change & $\beta$ & $R^{2}$ change & $F$ change \\
\hline \multirow[t]{4}{*}{1} & Age & $-0.01^{* *}$ & - & - & -0.01 & - & - \\
\hline & Gender (1 = women; 2 = men $)$ & $0.05^{* *}$ & - & - & 0.02 & - & - \\
\hline & Sector $($ public $=1 ;$ private $=2$ ) & $0.20^{* * *}$ & - & - & $0.20^{* * *}$ & - & - \\
\hline & In-role/extra-role performance at $\mathrm{T} 1$ & $0.63^{* * *}$ & 0.461 & $1449.53^{* * *}$ & $0.65^{* * *}$ & 0.438 & $1331.16^{* * *}$ \\
\hline \multirow[t]{2}{*}{2} & Emotional dissonance at $\mathrm{T} 1$ & $-0.05^{* *}$ & - & - & 0.01 & - & - \\
\hline & Cooperation with one's assistant at $\mathrm{T} 1$ & $0.10^{* * *}$ & 0.007 & $11.63^{* * *}$ & $0.14^{* * *}$ & 0.010 & $15.73^{* * *}$ \\
\hline 3 & $\begin{array}{l}\text { Emotional dissonance at T1 } \times \text { Cooperation } \\
\text { with one's assistant at T1 }\end{array}$ & $0.06^{*}$ & 0.002 & $4.90^{*}$ & $0.07^{*}$ & 0.001 & $4.14^{*}$ \\
\hline $\mathrm{R}^{2}$ & - & - & $47.0 \%$ & - & - & $45.0 \%$ & - \\
\hline \multirow[t]{4}{*}{1} & Age & $-0.01^{*}$ & - & - & -0.01 & - & - \\
\hline & Gender & $0.05^{* *}$ & - & - & 0.02 & - & - \\
\hline & Sector & $0.18^{* * *}$ & - & - & $0.17^{* * *}$ & - & - \\
\hline & In-role/extra-role performance at $\mathrm{T} 1$ & $0.62^{* * *}$ & 0.463 & $1530.26^{* * *}$ & $0.65^{* * *}$ & 0.425 & $1307.31^{* * *}$ \\
\hline \multirow[t]{2}{*}{2} & Emotional dissonance at T1 & $-0.03^{\mathrm{a}}$ & - & - & 0.03 & - & - \\
\hline & Optimism at $\mathrm{T} 1$ & $0.12^{* * *}$ & 0.008 & $14.31^{* * *}$ & $0.13^{* * *}$ & 0.11 & $16.43^{* * *}$ \\
\hline 3 & Emotional dissonance at $\mathrm{T} 1 \times$ Optimism at $\mathrm{T} 1$ & $-0.05^{*}$ & 0.001 & $4.73^{*}$ & 0.02 & 0.00 & 0.58 \\
\hline $\mathrm{R}^{2}$ & - & - & $47.1 \%$ & - & - & $43.4 \%$ & - \\
\hline
\end{tabular}

$* * * P<0.001 ; * * P<0.01 ; * P<0.05 ;{ }^{a} P<0.10$ 


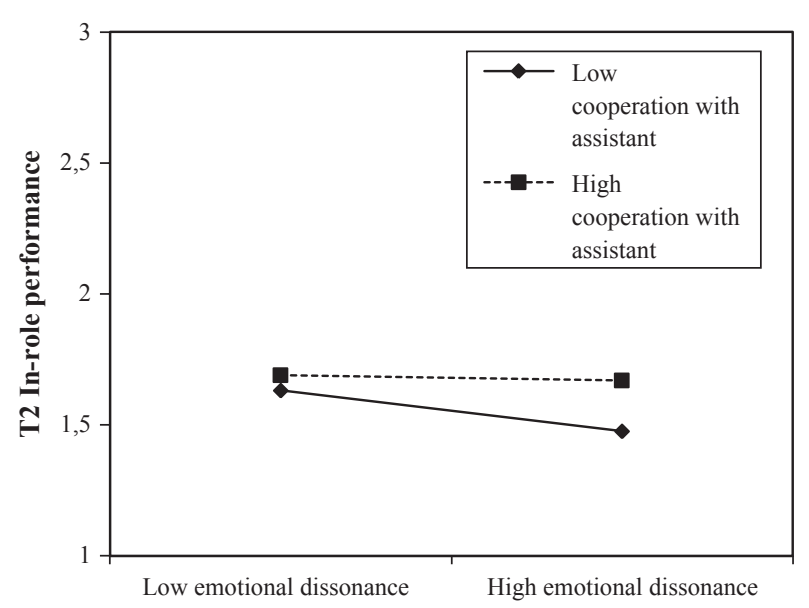

Fig. 1. Interaction effects of T1 emotional dissonance and T1 cooperation with one's assistant on T2 in-role performance.

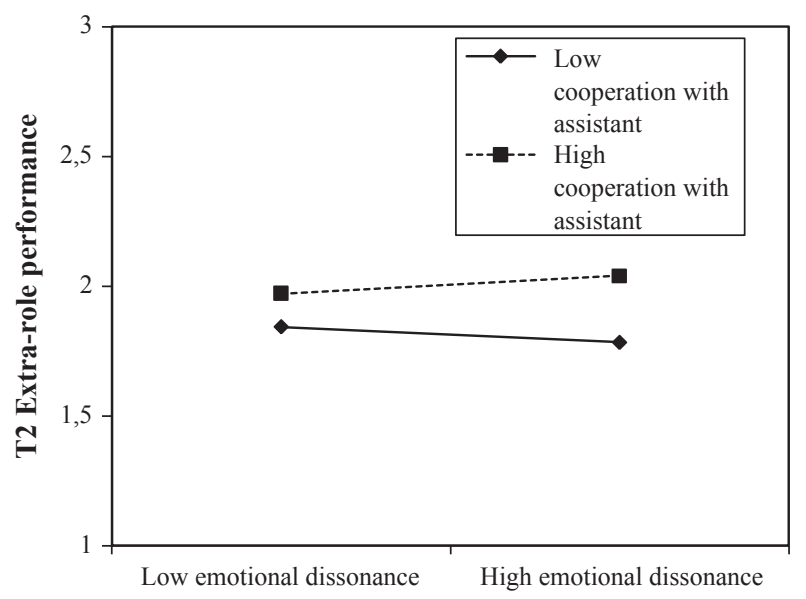

Fig. 2. Interaction effects of $\mathrm{T} 1$ emotional dissonance and $\mathrm{T} 1$ cooperation with one's assistant in predicting T2 extra-role performance.

emotional dissonance did not affect $\mathrm{T} 2$ in-role performance when there was a high level of good cooperation with one's assistant at T1. Similar results were found regarding T2 extra-role performance. In this sense, having high levels of T1 good cooperation with one's assistant buffered against the negative effect of emotional dissonance on T2 extra-role performance (Fig. 2).

As regards the personal resource of optimism, we discovered a different pattern because a significant interaction effect was only found in the case of $\mathrm{T} 2$ in-role performance, and not in T2 extra-role performance. Moreover, low (not high, as expected) levels of optimism buffered against the negative influence of emotional dissonance on T2 in-role performance. In other words, highly optimistic dentists have lower levels of T2 in-role

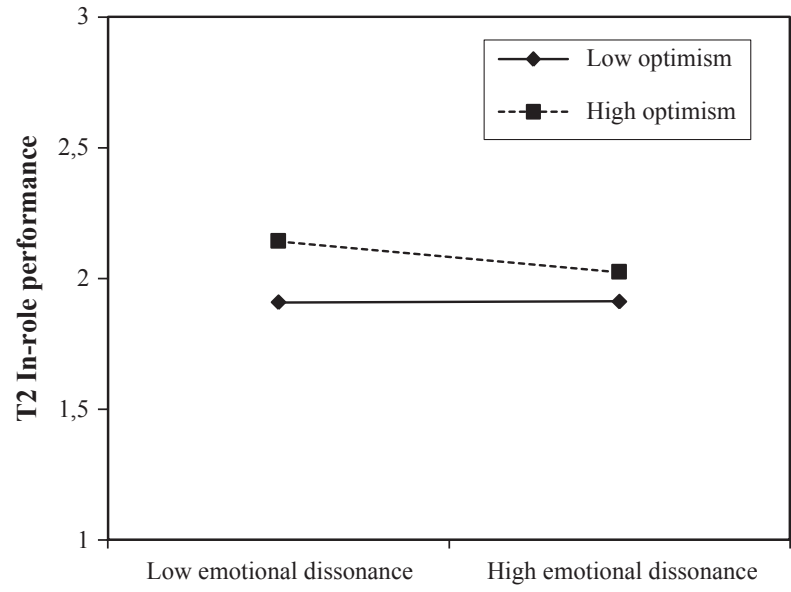

Fig. 3. Interaction effects of T1 emotional dissonance and $\mathrm{T} 1$ optimism in predicting $\mathrm{T} 2$ in-role performance.

performance in conditions of high emotional dissonance than in conditions of low emotional dissonance. All in all, we found support for the buffering role of cooperation with one's assistant (hypotheses 1a and 1b) but not for optimism (hypotheses $2 \mathrm{a}$ and $2 \mathrm{~b}$ ) (Fig. 3).

\section{Discussion}

The present study was based on the theoretical framework of the Job Demands-Resources Model (JD-R) (9) and its expansion (31) and aimed at testing whether good cooperation with a close coworker, that is, a dentist's cooperation with her/his assistant (an interpersonal job resource), and optimism (a personal resource) may buffer the negative effects of emotional dissonance on future in-role and extra-role performance. We tested our assertions along four hypotheses, and the findings partially supported our predictions. More specifically, the two hypotheses related to the buffering role of interpersonal job resources (cooperation with assistant) on in-role and extra-role performance in the long term were supported by our findings. However, the hypotheses related to the role of personal resources (optimism) as buffering the negative effects of emotional dissonance on inrole and extra-role performance in the long term were not supported.

Buffering role of job resources: cooperation with one's assistant

We found that a specific job resource, namely dentists' cooperation with their assistants, acted as a moderator of the negative effects of emotional dissonance on dentists' performance (both in-role 
and extra-role) over the 4-year follow-up period. In line with Berthelsen (27), the present work lends support to the idea that appreciative and supportive relationships with coworkers who provide feedback are a useful resource for coping with dentists' demands, especially emotional demands. In other words, when dentists experience high emotional dissonance (for instance dealing with a difficult patient) but at the same time perceive cooperation with their assistants as smooth and supportive, the negative long-term effects that emotionally demanding patient care may have on both their in-role and extra-role performance, will be reduced.

\section{Enigmatic role of personal resources: optimism} Whereas we found that interpersonal job resources do indeed play a buffering role, the hypotheses related to personal resources showed unexpected results. First, no significant over time interaction effect was found for extra-role performance, but only for in-role performance and in the unexpected direction. More specifically, in conditions of high emotional dissonance, dentists with high optimism showed lower levels of in-role performance in the long term than those with low emotional dissonance. Hence, how to explain the enigmatic role of optimism?

Previous studies have often linked optimism with positive outcomes (e.g., 36, 33). However, recent research agrees that the benefits (and costs) of optimism depend on its timing (47). Therefore, we need to look more closely at the settings, circumstances, antecedents, and consequences of optimism. Hence, the unexpected results of our study can be explained in several ways. First, to mitigate the negative effects of emotional dissonance, it seems that optimism as a personal resource is not enough to cope with such stressful demand in dental jobs. Instead, what is needed is the support of close coworkers, here dental assistants.

Second, it could be that too much optimism (over-optimism) might lead dentists to overestimate their ability to deal with emotionally adverse situations, resulting in lower performance in the future. In fact, our results are in line with those regarding other personal resources that are usually linked to positive outcomes such as self-efficacy. Thus, high levels of self-efficacy may turn into overconfidence in specific settings and lead to negative consequences for job performance (48).

Third, because optimism was conceptualized here as trait optimism, the results might have been influenced by the fact that emotional dissonance was experienced at the same temporal moment as we measured optimism, whereas performance measures correspond to the situation 4 years later. This is consistent with the finding that individuals 'currently' feeling optimistic at work are more likely to reap the benefits of optimism in terms of shorter term work-related outcomes (49). In other words, perhaps state optimism (but not trait optimism) is a predictor of important organizational outcomes. This issue is an important research target and should be studied from the viewpoint of trait versus state optimism's effects on performance. Finally, regarding the role of optimism as a personal resource, our results concur with some other research that points out that job resources can play a more active role in the prevention of negative outcomes (e.g., exhaustion) and personal resources are, up to a point, susceptible to environmental changes $(50,51)$. So all in all, the role of optimism is still unclear regarding emotional dissonance and performance, and in future research, it would be of interest to study the function of other personal resources, for example self-efficacy, in relation to emotional dissonance and performance in the long term.

\section{Practical Implications}

From a practical perspective, these findings point out that in dentistry, an emotionally highly demanding occupation, it is important to identify and strengthen the job resources that dentists have. These job resources affect not only dentists' health but also their performance. Simply increasing and improving the quality of cooperation between dentists and their assistants seems to be a good way in which to prevent the negative effects of emotional dissonance on long-term performance. Hence, organizations and management must be made aware of the relevance of training good teams and building a positive climate among colleagues to perform well. Feeling that one has sufficiently good cooperation with his/her assistant is a key issue, not only for in-role performance, but also for extra-role performance, because, as the song says: with a little help from my friends...

\section{Acknowledgements}

This research was supported by a grant from Fundació Caixa Castelló-Bancaixa (E-2010-28) and a grant from the Finnish Work Environment Fund (110152). 


\section{References}

1. Hochschild AR. The managed heart. Berkeley: University of California Press; 1983.

2. Croucher R, Osborne D, Marcenes W, Sheiham A. Burnout and issues of the work environment reported by general dental practitioners in the United Kingdom. Community Dent Health 1998;15:40-3.

3. Gorter RC, Albrecht G, Hoogstraten J, Eijkman MAJ. Work place characteristics, work stress and burnout among Dutch dentists. Eur J Oral Sci 1998;106:9991005.

4. Murtomaa H, Haavio-Mannila E, Kandolin I. Burnout and its causes in Finnish dentists. Community Dent Oral Epidemiol 1990;18:208-12.

5. Hülsheger UR, Schewe AF. On the costs and benefits of emotional labor: a meta-analysis of three decades of research. J Occup Health Psychol 2011;16:361-89.

6. Sideman Goldberg LS, Grandey AA. Display rules versus display autonomy: emotion regulation, emotional exhaustion, and task performance in a call center simulation. J Occup Health Psychol 2007;12: 301-18.

7. Bakker AB, Heuven E. Emotional dissonance, burnout, and in-role performance among nurses and police officers. Int J Stress Manag 2006;13:423-40.

8. Zapf D, Seifert C, Schmutte B, Mertini H, Holz M. Emotion work and job stressors and their effects on burnout. Psychol Health 2001;16:527-45.

9. Bakker AB, Demerouti E. The Job DemandsResources model: state of the art. J Manage Psychol 2007;22:309-28.

10. Gorter RC, Freeman R. Burnout and engagement in relation with job demands and resources among dental staff in Northern Ireland. Community Dent Oral Epidemiol 2011;39:87-95.

11. Grandey AA. Emotional regulation in the workplace: a new way to conceptualize emotional labor. J Occup Health Psychol 2000;5:95-110.

12. Zapf D, Vogt C, Seifert C, Mertini H, Isic A. Emotion work as a source of stress: the concept and development of an instrument. Eur J Work Organizat Psychol 1999;8:371-400.

13. Abraham R. Emotional dissonance in organizations: antecedents, consequences, and moderators. Genet Soc Gen Psychol Monogr 1998;124:229-46.

14. Morris J, Feldman DC. Managing emotions in the workplace. J Manage Issues 1997;9:257-74.

15. Rafaeli A, Sutton RI. Expression of emotion as part of the work role. Acad Manage Rev 1987;12:23-37.

16. Heuven E, Bakker AB. Emotional dissonance and burnout among cabin attendants. Eur J Work Organizational Psychol 2003;12:81-100.

17. Zapf D, Holz M. On the positive and negative effects of emotion work in organizations. Euro J Work Organizational Psychol 2006;15:1-28.

18. te Brake J, Bouman A, Gorter R, Hoogstraten J, Eijkman M. Using the Maslach Burnout Inventory among dentists: burnout measurement and trends. Community Dent Oral Epidemiol 2008;36:69-75.

19. Wegge J, Van Dick R, Bernstorff C. Emotional dissonance in call centre work. J Managerial Psychol 2010;25:596-619.

20. Abraham R. The impact of emotional dissonance on organizational commitment and intention to turnover. J Psychol 1999;133:441-55.
21. Goodman SA, Svyantek DJ. Person-organization fit and contextual performance: do shared values matter. J Vocat Behav 1999;55:254-75.

22. Bakker AB, Demerouti E, Verbeke W. Using the Job Demands-Resources model to predict burnout and performance. Human Resource Manag 2004;43:83104.

23. Bakker AB, Demerouti E, Euwema MC. Job resources buffer the impact of job demands on burnout. J Occup Health Psychol 2005;10:170-80.

24. Haines VA, Hurlbert JS, Zimmer C. Occupational stress, social support, and the buffer hypothesis. Work Occup 1991;18:212-35.

25. Xanthopoulou D, Bakker AB, Dollard MF, Demerouti E, Schaufeli WB, Taris TW et al. When do job demands particularly predict burnout?: the moderating role of job resources. J Managerial Psychol 2007;22:766-86.

26. Zapf D. Emotion work and psychological well-being: a review of the literature and some conceptual considerations. Human Resource Manag Review 2002;12:237-68.

27. Berthelsen H, Hjalmers K, Söderfeldt B. Perceived social support in relation to work among Danish general dental practitioners in private practices. Eur J Oral Sci 2008;116:157-63.

28. Berthelsen H, Hjalmers K, Pejtersen JH, Söderfeldt B. Good work for dentists - a qualitative analysis. Community Dent Oral Epidemiol 2010;38:159-70.

29. Van Emmerik I, Euwema MC, Bakker AB. Threats of workplace violence and the buffering effect of social support. Group Organizat Manag 2007;32:152-75.

30. Hobfoll SE, Johnson RJ, Ennis N, Jackson AP. Resource loss, resource gain, and emotional outcomes among inner city women. J Pers Soc Psychol 2003;84:632-43.

31. Xanthopoulou D, Bakker AB, Demerouti E, Schaufeli WB. The role of personal resources in the job demands-resources model. Int J Stress Manag 2007;14:121-41.

32. Hakanen JJ, Bakker AB, Schaufeli WB. Burnout and engagement among teachers. J Sch Psychol 2006;43:495-513.

33. Scheier MF, Carver CS, Bridges MW. Optimism, pessimism, and psychological well-being. In: Chang EC, editor. Optimism and pessimism: implications for theory, research, and practice. Washington DC: American Psychological Association, 2001; 189-216.

34. Iwanaga $M$, Yokoyama $H$, Seiwa $H$. Coping availability and stress reduction for optimistic and pessimistic individuals. Pers Indiv Differ 2004;36: $11-22$.

35. Luthans F, Youssef CM. Emerging positive organizational behaviour. J Manage 2007;33:321-49.

36. Mäkikangas A, Kinnunen U. Psychosocial work stressors and well-being: self-esteem and optimism as moderators in a 1-year longitudinal sample. Pers Indiv Differ 2003;35:537-57.

37. Sumi K, Horie K, Hayakawa S. Optimism, type A behavior, and psychological well-being in Japanese women. Psychol Rep 1997;80:43-8.

38. Garrosa E, Moreno-Jiménez B, Rodríguez-Muñoz A, Rodríguez-Carvajal R. Role stress and personal resources in nursing: a cross-sectional study of burnout and engagement. Int J Nurs Stud 2011;48:479-89. 
39. Nonis SA, Wright D. Moderating effects of achievement striving and situational optimism on the relationship between ability and performance outcomes of college students. Res High Educ 2003;44:327-46.

40. Seligman M. Learned optimism. New York: Pocket Books; 1998.

41. Chemers M, Watson C, May S. Dispositional affect and leadership effectiveness. A comparison of selfesteem, optimism, and efficacy. Personality Social Psychol. Bulletin 2000;26:267-77.

42. Hakanen JJ. HammaslääkäreidentyöhyvinvointiSuomessa [Work-related Well-being among Finnish Dentists]. Helsinki: Finnish Institute of Occupational Health and the Finnish Dental Association; 2004.

43. Scheier MF, Carver CS, Bridges MW. Distinguishing optimism from neuroticism (and trait anxiety, selfmastery, and self-esteem): a Re-evaluation of the Life Orientation Test. J Pers Soc Psychol 1994;67:1063-78.

44. Benyamini Y. Can high optimism and high pessimism co-exist? Findings from arthritis patients coping with pain. Pers Indiv Differ 2005;38:1463-73.
45. Chang L, McBride C. The factor structure of the Life Orientation Test. Educ Psychol Meas 1996;56:325-9.

46. Aiken LS, West SG. Multiple regression: testing and interpreting interactions. Newbury Park: Sage; 1991.

47. Sweeny K, Shepperd JA. The costs of optimism and the benefits of pessimism. Emotion 2010;10:750-3.

48. Salanova M, Lorente L, Martínez IM. The Dark and bright sides of self-efficacy in predicting learning, innovative and risky performances. J Span Psychol 2011;15:520-50.

49. Kluemper DH, Little LM, Degroot T. State or trait: effects of state optimism on job-related outcomes. J Organizat Behav 2009;30:209-31.

50. Luthans F, Avey JB, Avolio BJ, Norman SM, Combs GM. Psychological capital development: toward a micro-intervention. J Organizat Behav 2006;27:38793.

51. Mäkikangas A, Kinnunen U, Feldt T. Self-esteem, dispositional optimism, and health: evidence from cross-lagged data on employees. J Res Pers 2004; 38:556-75. 